\title{
THE SIGNIFICANCE OF THE OCCURRENCE OF BACTERIOPHAGE FOR DYSENTERY BACILLI IN WATER SUPPLIES
}

\author{
By A. J. RHODES, M.B. AND M. LUDLAM, M.B. \\ From the Bacteriology Department, University of Edinburgh
}

\section{INTRODUCTION}

For many years it has been a matter of common knowledge that bacteriophages can be easily isolated from water supplies. They were first demonstrated in water by Dumas in 1920, and many authors have since confirmed his observation (Arloing \& Chavanne, 1925; Manoliu \& Costin, 1925; Arloing \& Sempé, 1926; Bilouet, 1926; d'Herelle, 1926; Monteiro, 1926; Bujanowski, 1929; Gildemeister \& Watanabe, 1931; Stewart \& Ghosal, 1931-2; Schuurman \& Schuurman-ten Bokkel Huinink, 1934; Dienert, 1934; Vagedes \& Gildemeister, 1934; Panayotatou, 1935; Nick, 1936). These workers have recorded the presence of phages lysing dysentery, coliform, typhoid, paratyphoid, and, sometimes, cholera organisms in a wide variety of water supplies: e.g. lake, river, stream, canal and tap waters; phages have also been detected in sea water close to the shore.

As phages are known to be commonly present in the faeces of man and animals, no great importance was attached to their demonstration in water supplies, their presence being accepted as a general indication of faecal contamination.

Recently, however, interest has been aroused in the significance of phages in water by the work of Nisbet (1938), who, on the basis of detection of phage for dysentery bacilli, incriminated the water supply as the vehicle of infection in an epidemic of bacillary dysentery in the Scottish town of Kilmarnock. The tests were performed by Morison, who published a note explaining his technique (1938). No dysentery bacilli were isolated from the water during this outbreak, but their presence at some time was inferred from the fact that an agent lysing these organisms could be isolated from the water.

At the present time bacillary dysentery is widely prevalent in this country, and while the method of spread from case to case is often obscure, routine epidemiological investigations have not, as a general rule, caused suspicion to fall on water supplies. Accordingly, any technical method which may aid in investigating the possible role of water in the spread of dysentery is worthy of serious consideration.

We have had no difficulty in demonstrating the presence of phage for 
dysentery bacilli in various samples of water, and the present work has been undertaken with a view to evaluating the significance of these observations. It may be stated at once that our findings have led us to believe that the detection of phage for dysentery bacilli in a sample of water is not sufficient justification for postulating the contamination of that water by such bacilli, because it seems that such phage may be non-specific with regard to its relationship to dysentery bacilli.

\section{TeChNique USED To Demonstrate Phage in WATER}

The methods which we have employed for the detection of phage in water are essentially those described by Morison (1938), and can be recommended as admirably suited for this purpose.

(a) Method without enrichment. In this method 100 c.c. of the water to be tested are added to a flask containing an equal volume of yeastrel broth, and incubated overnight. A portion of this culture is then passed through a Chamberland L 5 candle and tested for the presence of phage as follows: Agar plates are stroked with broth cultures of various intestinal bacilli and, after the strokes have dried, the filtrate is dropped on to both ends of each stroke of culture. The plates are then incubated overnight and areas of lysis are looked for where the filtrate was dropped.

In only one out of the numerous tests made on raw and other water samples was phage detected by this method, in all the others an enrichment method had to be used. It is probable, however, that phage can only be detected without enrichment if present in some quantity, and that our specimens of water were not heavily contaminated and hence enrichment was needed.

(b) Enrichment method. In this method, water and broth are mixed as before but, in addition, about 1 c.c. of a young broth culture of a suitable organism is added (B. dysenteriae Gettings, B. dysenteriae Sonne, or B. coli). Incubation, filtration, and testing of the filtrate are carried out as before. By this method, phage was demonstrated frequently in samples of water. Lysis was usually pronounced $(+++)$, without secondary growth; sometimes, however, the effect was less pronounced and secondary growth occurred $(++$ or + ).

The organisms used for testing the lytic properties of the filtrates in both methods were the following: B. coli, B. typhosus, B. paratyphosus $\mathrm{A}$ and $\mathrm{B}$, B. enteritidis Gaertner, B. aertrycke, B. suipestifer, B. dysenteriae V, W, X, Y, $\mathrm{Z}$, Sonne, Shiga and Gettings.

Controls were carried out from time to time in which broth cultures of the enriching organisms were filtered and tested for possible lytic action on the test organisms. No such effect was ever produced.

\section{Results}

(a) Unenriched specimens. On only one occasion was phage detected in water which was simply added to broth and incubated before filtration and testing (Table I). 
Table I. Showing presence of phage in an unenriched sample

Unenriched sample*

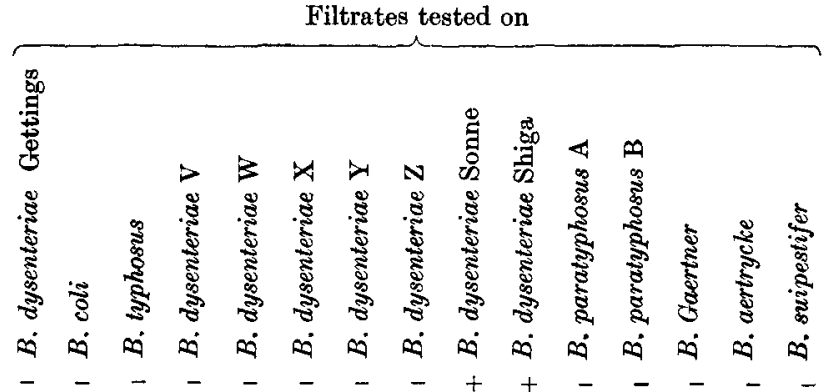

* In Tables $\mathrm{I}$ and $\mathrm{II},+++$ means complete lysis; ++ or + means weaker lysis with some secondary growth; - means no lysis.

Table II

Result when filtrates tested on

Enriched with

i. dysenteriae Gettings

$\therefore$ coli

. dysenteriae Sonne

- dysenteriae Gettings

. dysenteriae Gettings

$\therefore$ coli

i. dysenteriae Sonne

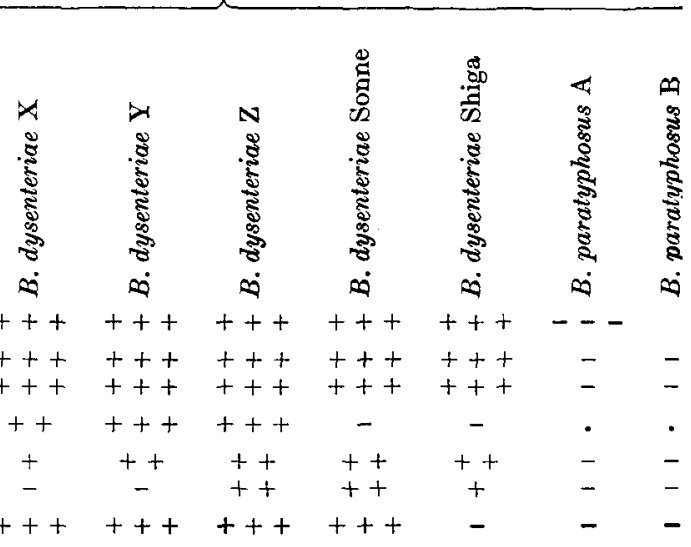


(b) Enriched specimens. Phage was frequently detected in water samples from various sources when enriched with $B$. dysenteriae Gettings, $B$. dysenteriae Sonne, or $B$. coli. When filtrates were tested on the homologous organism, well-marked lysis was usually produced. In addition to the effect on the enriching organism, usually lysis of many of the dysentery test cultures was noted as well. Lysis was frequently produced in the test stroke of $B . c o l i$ and on one occasion in the cultures of B. typhosus and two Salmonella organisms. A representative selection of a number of similar results is given in Table II. It should be noted that in all the examples quoted, tests were also conducted without enrichment, but with completely negative results.

\section{Prevalence of phage}

We have carried out experiments on numerous samples of water and have detected the presence of phage, with the general properties just described, in raw upland surface (loch) water supplying two large Scottish cities, in sandfiltered water from one of these cities, and from the distribution system of one of these cities and of one other town. Phage was not detected in a supply consisting of river water which had filtered through a natural bed of gravel; nor was it found in a small reservoir forming the private supply of a certain institution, situated inland.

An extensive study was made in the case of one Scottish city, where raw loch water was sand-filtered before passage to storage wells. Phage was readily detected in the samples of loch water examined, but the storage water from the wells contained no phage, showing that this particular filtration plant had removed the lytic principle. This, however, was not a universal experience as sand-filtered water from another Scottish city showed the presence of phage in two separate tests.

Phage for dysentery bacilli is well known to be widely distributed in the faecal contents of healthy men, of various animals, and especially of birds, apart from the presence of these bacilli themselves (see d'Herelle, 1926). The sources of the waters tested in this series of experiments excluded almost completely human faecal contamination and it seemed that the presence of phage could be accounted for mainly by contamination with the excreta of animals grazing beside the lochs, and of gulls.

A special investigation was made to search for the presence of lysogenic coliform strains in the faeces of gulls. This involved plating the intestinal contents of five gulls (which had been shot at a certain reservoir), and the isolation of sixteen strains of $B$. coli. All strains were inoculated into yeastrel broth and incubated for 10 days. After this period, a filtrate (Chamberland L 5) was prepared and tested for possible lytic effect on stroke cultures of dysentery bacilli on agar plates. If no phage was detected, then a portion of the filtrate was added to a young growing culture of the same strain of $B$. coli, which was reincubated and the filtration and testing repeated.

J. Hygiene $\mathbf{x} \times \mathbf{x i x}$ 
When the second filtrate was tested, strain no. 14 produced a lytic effect on Gettings, W, and Sonne dysentery bacilli, and when the third filtrate was tested strain no. 2 produced a lytic effect on Gettings, Y, and Shiga bacilli. The remaining 14 strains never showed any phage. Strain 2 was further investigated as follows: The culture was inoculated into yeastrel broth and, after 2 weeks' growth, filtrates were tested on dysentery bacilli and found to lyse Gettings and $\mathrm{Y}$ bacilli. An attempt was made to raise the virulence of the phage carried by strain 2 by enriching the lytic filtrate with $B$. dysenteriae $Y$. This did not succeed, and an enriched filtrate showed no lytic properties. McKie (1934) also experienced difficulty in passaging phages from lysogenic bacilli, and found that a number were lost. In another experiment strain 2 , growing in broth, in as short a period as $24 \mathrm{hr}$. produced phage for Gettings and $\mathrm{Y}$ bacilli.

In short, two strains of $B$. coli isolated from gulls have been shown to carry phage which lyses dysentery bacilli.

\section{Discussion}

We have shown that a lytic agent for dysentery bacilli can be isolated from samples of municipal water supplies with comparative ease, and this investigation was undertaken in order to ascertain its significance. For the detection of phage in the particular specimens examined, enrichment has in our experience been practically always necessary, but it is not necessary to use a dysentery bacillus, for $B$. coli serves the purpose quite adequately. After enrichment by such cultures, the filtrates are found to produce lysis in the test strokes of dysentery bacilli and often of B. coli; Salmonella organisms also may be lysed.

It is evident, therefore, that the lytic agent cannot be considered as bearing a specific relationship to dysentery bacilli for it can be produced by enrichment with $B$. coli, and even when produced by enrichment with a dysentery bacillus frequently lyses $B$. coli. Further, it has been shown that gulls may harbour strains of $B$. coli which carry a phage capable of lysing dysentery bacilli.

In conclusion, we think that the finding in water supplies of a phage for dysentery bacilli is not by itself sufficient proof that the water in question is contaminated by these pathogenic organisms. In fact, the presence of phage is no more than an index of faecal contamination, and is of little value in the epidemiological investigation of outbreaks of bacillary dysentery.

\section{SUMmaRY}

1. Bacteriophage has been demonstrated in various municipal water supplies in Scotland.

2. This phage acts both on dysentery and coliform bacilli, and can be produced by enrichment with organisms belonging to either of these types.

3. Examination of sixteen strains of $B$. coli isolated from gulls showed that two were lysogenic, carrying lytic agents for dysentery bacilli. 
4. The presence in water supplies of a phage acting on dysentery bacilli is itself no evidence that such waters are contaminated with dysentery bacilli.

We wish to acknowledge our indebtedness to Prof. W. J. Tulloch, who took an active interest in this inquiry and assisted by the collection of suitable samples of water, and to Prof. T. J. Mackie for his constant help and advice during the progress of the investigation.

\section{REFERENCES}

Arlonna, F. \& Chavanne (1925). C.R. Soc. Biol., Paris, 92, 257.

Arlonva, F. \& Sempé (1926). C.R. Soc. Biol., Paris, 94, 191, 428.

BILOTET, V. (1926). C.R. Soc. Biol., Paris, 94, 708.

BuJanowskr, D. (1929). Z Zbl. Bakt. Abt. I. Orig. 110, 120.

D'Herelle, F. (1926). The Bacteriophage and its Behavior. Translated by G. H. Smith.

London: Baillière, Tindall \& Cox.

Dienert, F. (1934). Bull. Acad. Méd. Paris, 112, 611.

Dumas, J. (1920). C.R. Soc. Biol., Paris, 83, 1314.

Gitdemeister, E. \& Watanabe, H. (1931). Zbl. Bakt. Abt. I. Orig. 122, 556.

McKIE, M. (1934). Aust. J. exp. Biol. med. Sci. 12, 169.

Manoliu, E. \& Costin, G. (1925). C.R. Soc. Biol., Paris, 93, 384.

Monteiro, J. L. (1926). C.R. Soc. Biol., Paris, 95, 994.

Monisov, J. (1938). Med. Offr. 59, 89.

NiCK, J. (1936). Zbl. Bakt. Abt. I. Orig. 136, 397.

NisBet, B. R. (1938). Med. Offr. 59, 87.

Panayotatod, A. (1935). Bull. Acad. Méd., Paris, 114, 493.

Schudrman, C. J. \& Schudrman-ten Bokkel Huinink, A. M. (1934). Zbl. Bakt. Abt. I. Orig. 132, 321.

Stewart, A. D. \& Ghosal, S. C. (1931-2). Indian J. Med. Res. 19, 137.

v. VaGedes, K. \& GILDEMeISTer, E. (1934). Zbl. Bakt. Abt. I. Orig. 131, 414.

(MS. received for publication 31. vII. 39.-Ed.) 